\title{
A Influência Do Gênero Feminino Sobre A Ocorrência De Assédio Moral: Um Estudo Em Uma Rede De Postos De Combustível Na Cidade De Maringá
}

\section{The Influence Of Feminine Gender On The Occurrence Of Bullying At Work: A Study In Fuel Station Campanies In The City Of Maringá}

\author{
Camilla Ariane Ajita Picironi ${ }^{1}$, Cleiciele Albuquerque Augusto ${ }^{1}$ \\ ${ }^{1}$ Universidade Estadual de Maringá, UEM, Brasil. \\ Correspondência: Cleiciele Albuquerque Augusto. Av. Colombo, 5790, Jardim Universitário, CEP 87.020-900, \\ Maringá, PR, Brasil. Telefone: +55 (44) 3011-4906. E-mail: cleicielealbuquerque @ yahoo.com.br.
}

Recebido: 25 de julho de 2017 Aceito: 29 de setembro de 2018 Publicado: 28 de dezembro de 2018

DOI: http://dx.doi.org/10.21714/1679-18272018v16n1.p30-42

\begin{abstract}
Resumo
O presente estudo tem como objetivo compreender a influência do gênero sobre as ocorrências de assédio moral. Deriva-se a necessidade de se estabelecer a relação entre assédio moral e gênero, a fim de se explicitar qual o comportamento do gênero na prática do assédio, identificando eventuais causas e circunstâncias que determinam a reprodução deste comportamento no ambiente de trabalho. $\mathrm{O}$ artigo vislumbra ainda a legislação pátria sobre o assunto, bem como o perfil do assediado e medidas efetivas para o combater e prevenir o assédio moral. $\mathrm{O}$ estudo é qualitativo e utilizou-se um primeiro momento de uma pesquisa bibliográfica. Em seguida, em uma pesquisa de campo de natureza descritiva, foram entrevistadas 9 mulheres de uma mesma rede de postos de combustíveis de Maringá. Os achados revelam um ambiente de trabalho mais salutar para a mulher, quando confrontado com a literatura já existente sobre o tema e os resultados esperados. Conclui-se que, embora o trabalho da mulher demonstrou-se reconhecido e valorizado nos postos de combustíveis investigados, ainda existem variáveis que influenciam na perpetuação da discriminação da mulher em razão do gênero em ambientes masculinazados.
\end{abstract}

Palavras-chave: Assédio moral, Gênero feminino, Direitos da Personalidade, Postos de Gasolina.

\begin{abstract}
The present study aims to understand the influence of gender on the occurrences of moral harassment. The need to establish a relationship between harassment and gender is important to understand the relevance of gender in the practise of harassment, identifying possible causes and circumstances that determine the reproduction of this behavior in the workplace. The article covers the brazilian law on the subject, the profile of the victim of harassment and effective measures to combat and prevent bullying. The study is qualitative and includes a bibliographical research. A field survey of a descriptive nature was conducted in which 9 woman from a Maringá fuel station company were interviewed. The findings reveal a healthier work enviroment for woman when confronted with existing literature on the subject and expected results. Although the work of woman has been recognized at the fuel stations investigated, there are still variables that influence the perpetuation of discrimination based on gender.
\end{abstract}

Keywords: Harassment, Bullying, Gender, Personality Rights, Gas stations.

Esta obra está licenciada sob uma Licença Creative Commons Attribution 3.0.

\section{Introdução}

As discussões acerca do assédio moral têm ganhado espaço nos últimos anos, em função da crescente demanda do judiciário em relação ao tema, bem como a exposição na mídia das mais diversas reinvindicações dos direitos laborais.

De acordo com Barreto (2008), essas discussões têm sido relevantes, uma vez que as transformações da sociedade, em especial no mundo do trabalho, impactaram diretamente na maneira em que as relações são construídas dentro 
das organizações. Primeiramente, há que se falar na reestruturação das empresas onde tem-se observado a flexibilização dos direitos do trabalhador, o que abarca a questão do tempo e da saúde do trabalhador. Em um ambiente voraz e competitivo, a jornada de trabalho não mais se estende aos espaços físicos da organização e o trabalhador passa estar 24 horas a disposição do trabalho, submetendo-o a um nível de pressão e estresse prejudicial a sua saúde (BARRETO, 2008).

Para Barreto (2008), há que se ressaltar a questão da empregabilidade em que é de responsabilidade do trabalhador renovar-se continuamente com o intuito de se enquadrar sempre nas demandas emergentes do mercado. Todas essas transformações e a ameaça do desemprego criaram um terreno propício para a perpetuação do assédio moral no ambiente de trabalho o que levou a uma crescente procura do judiciário tendo como objeto o assédio moral nas relações empregatícias, diga-se de difícil prova, mas extremamente gravosa para a saúde do trabalhador (BARRETO, 2008).

Ademais, é importante salientar o tratamento díspar que se perpetuou por décadas entre homens e mulheres no ambiente de trabalho, restando ainda traços de uma cultura patriarcal que oprimiu as mulheres e as privou de muitos direitos que lhe eram devidos (GOLDANI, 2000).

O assédio moral foi pioneiramente objeto de estudo nos países escandinavos (EINARSEN E SKOGSTAD, 1996; LEYMANN E GYSTAFSSON, 1996). No Brasil o tema tem sido pouco explorado, portanto, daí deriva-se a necessidade de se estabelecer a relação entre o assédio moral e gênero feminino, a fim de se explicitar qual o comportamento do gênero na prática do assédio, identificando eventuais causas e circunstâncias que determinam a reprodução deste comportamento no ambiente de trabalho, buscando compreender como a construção da imagem da mulher em ambientes de predominância masculina e como sua presença implica em situações de assédio moral contra elas.

Ainda não foram realizadas pesquisas que abordem o assédio moral em postos de gasolina, portanto, a presente investigação visa esclarecer a temática no setor de comércio de combustíveis. É certo que o ambiente de trabalho em postos de gasolina é predominantemente masculino pela própria natureza do trabalho, a qual é dotada de um alto grau de periculosidade pela constante manipulação de líquidos explosivos, razão pela qual menos mulheres se candidatem ao emprego de frentista. A predominância masculina, por sua vez, facilita a ocorrência de assédio moral contra as poucas mulheres que ali trabalham por formarem um grupo de minorias que é fragilizado pelo ambiente hostil a sua volta. Por esse motivo, a presente investigação visa esclarecer a temática no segmento.

Considerando o contexto e consciente dos danos e malefícios da propagação do assédio moral no ambiente do trabalho, este trabalho procura responder como o gênero pode influenciar a ocorrência de assédio em uma rede de postos de combustíveis de Maringá. Levando ainda em consideração as situações denotam assédio moral na percepção dos entrevistados, bem como quais as possíveis maneiras que afastar esse fenômeno do ambiente do trabalho.

Dito isso, o presente trabalho tem como objetivo geral compreender a influência do gênero sobre as ocorrências de assédio moral em uma rede de postos de combustíveis na cidade de Maringá, Paraná. Diante disso, os objetivos específicos traçados buscam: a) compreender como a imagem da mulher é construída em ambientes de predominância masculina, na visão das mulheres entrevistadas; b) identificar as situações que indicam a ocorrência de assédio moral contra as mulheres investigadas; c) descrever quais medidas podem ser tomadas para evitar o assédio moral, na percepção das mulheres investigadas;

A presente investigação está alicerçada em bases teóricas e práticas. Em se tratando da teoria, observa-se uma baixa produção científica em relação ao assunto, já que o assédio moral é um tema atual e pouco havia se discutido sobre isso até então. Além disso, são escassos os trabalhos que tragam à tona a relação entre o assédio moral e gênero, promovendo uma discussão sobre a relevância do gênero na ocorrência de agressões físicas e psíquicas no ambiente de trabalho. Deste modo, entende-se necessário levantar pontos de discussão que esclareçam questões pertinentes ao tema, mais especificamente, no setor de postos de combustíveis.

Já em relação a justificativa prática do trabalho, tendo em vista a grande diversificação na qual o mercado de trabalho tem se desenvolvido, bem como a ruptura dos conceitos de gênero que se limitavam a classificar homens e mulheres de acordo com seu papel sexual (MACHADO, 1992), o presente trabalho mostra-se importante por explicitar um problema vivenciado cotidianamente pelos trabalhadores. Cada vez mais mulheres tem assumido papéis que antes eram pertinentes somente a homens no mercado de trabalho, contudo, apesar da ruptura de muitas barreiras sociais, é possível ainda se observar traços de uma cultura machista e patriarcal em ambientes de predominância masculina que, por sua vez, são a raiz de comportamentos ofensivos contra as mulheres (HIRIGOYEN, 2006).

Dessa maneira, é relevante investigar quais as possíveis causas do assédio moral e as circunstâncias em que essas agressões se manifestam, bem como entender quais medidas são capazes de afastar comportamentos agressivos e 
perturbadores, gerando com isso, o ambiente de trabalho saudável e respeitoso para homens e mulheres, independente de haver dentro dele a predominância de um sexo em detrimento de outro.

\section{Revisão de Literatura}

\subsection{Gênero: Conceito}

De acordo com Goldani (2000), o ambiente organizacional sempre foi marcado pela construção de relações de dominação assimétricas no que tange a divisão sexual que nele pode ser observada. A mulher foi historicamente marginalizada e segregada no ambiente do trabalho quando a questão envolvia controle e distribuição de poder. A construção do ambiente organizacional apenas remonta marcas de uma sociedade que privou por séculos as mulheres de muitos direitos que lhe eram devidos e as relações de trabalho construídas dentro das organizações nada mais eram reflexos do mundo externo.

Para o autor supracitado, a sociedade caminhou a lentos passos e mudanças significativas aconteceram, o que refletiu diretamente no ambiente econômico e cultural, revolucionando a realidade da mulher no mercado de trabalho, por meio de um discurso embasado na libertação do sexo feminino e emancipação de uma condição de supressão. Expandiu-se o consenso que homens e mulheres eram igual de pleno direito e para o efetivo desenvolvimento econômico e social de um país era necessária a disseminação da igualdade entre os sexos. Daí emergiu o conceito de gênero:

Gênero é, na verdade, a representação de uma relação, a relação de pertencer a uma classe, um grupo, uma categoria. O gênero constrói uma relação entre uma entidade e outras entidades previamente constituídas como uma classe, uma relação de pertencer. Assim, gênero representa não um indivíduo e sim uma relação, uma relação social, em outras palavras, representa um indivíduo por meio de uma classe (GOLDANI, 1999, p.6).

Na visão de Souza (2002), o movimento Feminista que ganhou espaço no século XIX foi de extrema importância na constituição de um conceito de gênero que emergiu entre estudiosas feministas que buscavam refutar o determinismo biológico como argumento que pudesse explicar os comportamentos de homens e mulheres e que consolidasse, então, uma visão naturalizada e imutável dos comportamentos.

Dessa maneira, Stuart Hall (2002) afirma que o Feminismo trouxe à tona aspectos novos que começou como um movimento voltado à contestação da posição social e expandiu-se também para constestar a formação das identidade sexuais e de gênero.

Para Saffioti (1992), as relações reproduzem conceitos de gênero absorvidos por homens e mulheres, em vista que o machismo não é uma prerrogativa apenas dos homens, a maioria das mulheres também são portadoras dele.

Com isso, Goldani (2000) entende que as políticas de igualdade de oportunidade devem visar o bem-estar social de homens e mulheres, entretanto, deve-se ter em mente a situação da cidadania fragilizada das mulheres constituída ao longo da história.

Com relação a imagemda mulher em ambiente de trabalho de predominância masculina, Barreto (2000) acredita que as pessoas mais vulneráveis a se tornarem vítima do assédio moral são aquelas que apresentam diferenças com os padrões estabelecidos naquele ambiente, isso porque a discriminação é característica inerentes ao assédio. Logo, a presença de mulheres em ambientes em que a predominância seja de homens torna o meio hostil para elas, tornando-as vulneráveis e propensas a serem vítimas de assédio, bem como homens que laboram em ambientes predominantemente femininos, tendem a sofrerem discriminação em razão do gênero. Vale ressaltar que para o presente estudo, vulnerabilidade pode ser compreendida como um conjunto de fatores de natureza biológica, epidemiológica, social e cultura cuja interação amplia ou reduz o risco ou a proteção de uma pessoa perante a alguma pessoa, risco ou dano.

Hirigoyen $(2005$, p. 100) assegura que "as mulheres não somente são frequentemente vítimas, como também são assediadas de formas diferentes dos homens: as conotações machistas ou sexistas estão muitas vezes presentes".

Ainda nessa esteira, Hirigoyen (2006) elenca como facilitadores do assédio motivos raciais, religiosos, ou ainda em razão de deficiência física ou doença; orientações sexuais e de gênero. A autora ressalta também como possíveis vítimas as pessoas atípicas, aquelas que podem ser consideradas demasiadamente competentes, aliadas a grupos divergentes da administração ou pessoas consideradas improdutivas.

Investigações anteriores realizadas no Brasil e no exterior também revelam que o gênero é fator determinante na hora de se estabelecer um perfil para os assediados. Leymann (1996) um dos maiores expoentes mundial acerca do assédio moral, em pesquisa realizada na Suécia descobriu que mulheres representavam $55 \%$ do total de assédio moral sofrido no trabalho, sendo que homens assediavam homens e mulheres assediavam mulheres. 


\subsection{Assédio Moral: Conceito e Particularidades}

De acordo com Leymann (1996), o assédio moral no ambiente de trabalho pode ser entendido como comportamentos e ações hostis praticadas reiteradamente contra um ou mais trabalhadores, de maneira consciente ou inconsciente e que afeta de forma negativa a integridade psíquica ou física do trabalhador, o que pode ocasionar em consequências no desempenho do trabalho e o no ambiente de trabalho. Pode ser caracterizado como condutas abusivas que objetivam agredir psiquicamente e/ou fisicamente o empregado. (LEYMANN, 1996).

Para o autor supracitado, esses comportamentos devem ser sistemáticos, o que implica dizer que devem ocorrer ao menos uma vez por semana e com uma certa duração de tempo, qual seja, ao menos por seis meses. Vale ressaltar que o assédio moral tem caráter interdisciplinar uma vez que engloba áreas da psicologia, medicina do trabalho, administração de empresas e etc.

Marie France Hirigoyen (2006) define como assédio moral toda conduta abusiva que engloba gestos, palavras, comportamentos, atitudes que por sua repetição violam a dignidade ou a integridade de uma pessoa, colocando em perigo seu emprego ou depredando seu ambiente de trabalho. É importante frisar ainda que a autora afirma que o assédio se caracteriza de forma essencial pela sua reiteração, entretanto, diferente do que afirma Leymann (1996), para a psicóloga francesa, estabelecer um padrão de frequência como ao menos uma vez por semana e um período mínimo de seis meses é banalizar a gravidade do assédio, porque a caracterização da ocorrência do assédio não deve depender exclusivamente da sua duração. Contudo, deve-se também considerar a violência da agressão como fator determinante, uma vez que atitudes humilhantes são capazes de degradar a saúde do trabalhador antes mesmo de se completarem os seis meses (LEYMANN, 1996).

Outro ponto destacado por Hirigoyen (2005) no que tange a caracterização do processo de assédio moral é a intencionalidade. Quando se trata de uma agressão psicológica não é possível afastar a questão da intencionalidade, dado que o caráter intencional de uma agressão potencializa o impacto de tal atitude. Para a autora a intencionalidade é crucial na hora de distinguir efetivamente o assédio moral de más condições de trabalho e isso se justifica pelo fato do assédio moral ser um abuso do qual não deve equivocar-se com decisões legítimas inerentes à organização do trabalho, visto que é natural de todo trabalho que este seja permeado de certo grau de imposição e exigência.

O processo de assédio moral pode ainda ser qualificado pela assimetria e desiquilíbrio na relação em que ele se manifesta, onde uma parte julga-se melhor que outra:

Aquele que põe em ação a violência define-se como superior ao outro, o que é, em geral, aceito por aquele que recebe a violência. Cria-se, portanto, uma relação entre dominante e dominado que nada tem ligação com um simples conflito, já que o agressor submete a vítima a reiteradas humilhações a ponto de fazê-lo perder a sua identidade (HIRIGOYEN, 2005, p. 135).

Para Barreto, Heloani e Freitas (2008) é usual que o assédio moral se manifeste de um modo insignificante, o que pode facilmente ser confundido com uma brincadeira de mau gosto, que leva a vítima a negligenciar o problema, encarando-o de maneira mais branda, sem que ele seja levado a uma formalização como problema organizacional. Como a reiteração das atitudes ofensivas é a particularidade mais notável do assédio, leva tempo até que a vítima se atente que os ataques são cada vez mais recorrentes, consequência disso é a vítima com o passar de o tempo tornar-se mais frágil, vulnerável e impotente para reagir as agressões de forma eficaz, já que as inúmeras ofensas têm o poder de a desestabilizar emocionalmente (BARRETO; HELOANI; FREITAS, 2008).

Hirigoyen (2006) compartilha dessa mesma ideia e afirma que as condutas se iniciam como algo que parece inofensivo, todavia, se perpetuam de maneira silenciosa já que a vítima a princípio não se mostra ofendida e leva na brincadeira. Porém, com o decorrer do tempo, os ataques tendem a se multiplicarem e acuarem a vítima, submentendo-a a situações ofensivas e degradantes. A vítima por sua vez, assume quase sempre um papel passivo frente a agressão, posto que não tem consciência da violência psicológica lhe é empregada, muito embora admita e reconheça o sofrimento, não tem percepção de fato da agressão (HIRIGOYEN, 2006).

Barreto (2008) expoente das pesquisas em assédio moral no Brasil, define o assédio como sendo a exposição dos trabalhadores a situações humilhantes e constrangedoras, repetitivas e prolongadas durante a jornada de trabalho e no exercício de suas funções.

Para Barreto (2008) o assédio moral nunca se apresenta a princípio como assédio. Ele tem origem em uma situação de conflito não resolvido. Dessa forma, ressalta-se a necessidade de destacar a diferença entre conflito e assédio moral. Para a autora, o conflito deve ser encarado como algo positivo, visto que por meio dele podem decorrer novas ideias levando ao crescimento mútuo, embasado em uma comunicação respeitosa e envolvendo tarefas bem definidas. Por outro o lado, o assédio é eivado de falta de ética e de uma comunicação deturpada e imperativa, onde as tarefas são confusas e as ordens ambíguas. Portanto, para que o assédio possa ser evitado e combatido, 
acredita-se necessário uma intervenção durante o conflito, antes que ele se transforme em assédio moral propriamente dito (BARRETO, 2008).

\subsubsection{Direitos da personalidade e a legislação brasileira}

Para que se possa discutir o assédio moral é necessário antes ser levantada a questão dos denominados direitos da personalidade. Segundo Diniz (2002), os direitos da personalidade são aqueles que tutelam os bens mais elevados e supremos da pessoa humana. São caracterizados por sua essencialidade, pois não há pessoa que não possua esses direitos, o que significa dizer que a existência do ser humano já é condição para a presença dos direitos da personalidade, uma vez que por meio desses direito o homem consegue viver com dignidade.

Posto isso, resta ressaltar que os direitos da personalidade dão origem a todos outros direitos, nenhum outro direito vem à tona sem antes encontrar fulcro nos direitos da personalidade como a vida, a honra e a integridade física. É válido ressaltar que os direitos da personalidade são essenciais, absolutos, irrenunciáveis, intransmissíveis, imprescritíveis e inatos a qualquer ser humano. Portanto, todo assédio, antes de qualquer coisa, é a tipificação da violação a qualquer dos direitos da personalidade (DINIZ, 2002), qual seja também a violação do Princípio da Dignidade Humana prevista na Constituição Brasileira.

Goldani (2000) acredita que no Brasil a legislação se mostra bastante sólida no que tange os direitos e a igualdade entre homens e mulheres. Contudo, segundo o autor, sabe-se que isto não é bastante para afastar as representações sociais construídas em relação aos papéis e atribuições de homens e mulheres, a questão da igualdade de oportunidades tem raízes mais profundas e complexas do que as bases legais delineadas no nosso país, aspectos sociais e culturais ainda se fazem muito presentes e influenciam na organização do trabalho dentro das empresas.

Atualmente no Brasil não existe uma lei específica federal que verse sobre o assédio moral, muito embora a procura do judiciário para se denunciar esse tipo de agressão tenha elevado substancialmente nos últimos anos (UFSC, 2013).

Outra limitação encontrada é a verificação do nexo causal entre a agressão sofrida pela vítima e o dano causado, dessa forma, a identificação do assédio moral, por vezes, necessita de subsídios maiores, além do posicionamento do assediado, como por exemplo provas materiais e testemunhas que presenciaram as atitudes ofensivas. Ainda nesse sentido, uma vez que o assédio consiste em uma violência psicológica, medidas legislativas se mostram muitas vezes ineficazes de refutar o processo de assédio moral (UFSC, 2013).

Logo são utilizadas legislações que amparam os direitos da personalidade, como é o caso da Constituição Federal, em seu artigo 1, inciso III que resguarda dignidade da pessoa humana. Ademais, o Código Civil de 1988 traz em seu artigo 186: "aquele que, por ação ou omissão voluntária, negligência ou imprudência, violar direito o causar dano a outrem, ainda que exclusivamente moral, comete ato ilícito". E por fim, o artigo 483 da Consolidação das Leis Trabalhistas legitima a rescisão unilateral do contrato de trabalho pelo empregado em ocasiões em que a empresa cometer uma falta grave, como é o caso do assédio moral (UFSC, 2013).

\subsubsection{Situações que indicam a ocorrência de assédio moral}

Guedes (2004) classifica algumas atitudes como assédio moral, como se recusar a comunicar-se, desqualificar e constranger alguém a fim de destruir sua auto estima e cortar as relações sociais. Entretanto, identificar essas situações não é algo simples porque são dotadas de um alto grau de subjetividade, ademais, averiguar as consequências dessas atitudes nas vítimas é também difícil, ainda que os sintomas sejam manifestos, como o estresse, a depressão e a síndrome do burn out. Sobre o mesmo aspecto, compartilham do mesmo pensamento, Pineul e Zabala (2003) que indicam também como assédio moral comportamentos de omissão de informações, recusa de comunicação, isolamento e discriminação, desqualificação dos serviços e indução ao erro.

É importante assinalar, dessa forma, situações que não constituem assédio moral e devem ser encaradas apenas como conflitos que naturalmente fazem parte das organizações, como é o caso do stress, das agressões físicas e verbais ocasionais que não tenham sido premeditadas ou intencionais, das condições da saúde insalubres e perigosas e dos constrangimentos profissionais que decorram do poder hierárquico e disciplinar na empresa, como por exemplos avaliações e processos disciplinares (HIRIGOYEN, 2002).

Ainda nessa esteira, não pode ser identificado como assédio as situações eventuais de humilhação e constrangimento, ainda que intencionais. A configuração de assédio carece de comportamentos repetitivos que ocorram com uma certa frequência, logo, um comportamento isolado não constitui assédio moral, não obstante, possa ser passível de dano moral. Ademais, exigências profissionais inerentes da relação de trabalho como cobranças, críticas construtivas e avaliações sobre o trabalho também não cabem como assédio moral (UFSC, 2013). 
Atualmente, sob a ótica de Christ (2011), o instrumento mais relevante para a identificação do assédio moral nas organizações é o Negative acts Questonnaire Revised (NAQ-R) criado por Einarse, Raknes, Mattiesen e Hellesay na Noruega. $\mathrm{O}$ instrumento de propõe a avaliar o assédio moral, apontando para tanto 22 itens que sugerem situações de comportamentos agressivos sem que termo "assédio" seja citado.

\subsubsection{Medidas para evitar o assédio moral}

Para que o assédio não se perpetue no ambiente de trabalho, Silva (2007) entende que são necessárias uma série de medidas internas e externas a organização, com ênfase naquelas medidas que contribuam para a prevenção do comportamento agressivo. Acredita-se que o próprio Estado tem o dever de legislar em favor das vítimas, por meio de sanções destinadas aos agressores.

Sabe-se que a doutrina jurídica propõe medidas que possam prevenir os acidentes de trabalho, bem como as enfermidades advindas dele, buscando assegurar ao trabalhador pelas condições de segurança e saúde no ambiente de trabalho. Contudo, entende-se necessário maiores respaldos legais em relação a penalização do assédio a fim de coibir essas agressões de maneira mais efetiva (SILVA, 2007).

Já em relação a prevenção por parte do empregador, Barreto (2008) acredita que é necessário que as organizações realizem uma prevenção primária em relação ao assédio que envolva a realização de campanhas de sensibilização antiviolência, elaboração de cartilhas e material informativo. Caso reste insuficiente a prevenção primária, é possível que seja fundamental a criação de grupos de apoio e reconhecimento do problema, elegendo assim um mediador capaz de auxiliar as partes a chegarem num consenso, e em último plano, deve-se reorganizar o trabalho visando prevenir o risco de perseguição psicológica. É necessário que se construa uma cultura de prevenção que abarque a segurança e a saúde do trabalhador que esteja alinhada com o contexto da globalização.

Freitas, Heloani e Barreto (2008) acordam que para afastar o assédio é preciso: "erradicar a cultura da impunidade, da falta de respeito, da promiscuidade e da indigência moral no ambiente de trabalho é tarefa coletiva, que precisa da cooperação dos ocupantes de cargos mais elevados. "

Para Einarsen e Hoel (2008) a prevenção do assédio moral engloba elementos como a criação de um clima social respeitoso, em que a diversidade seja aceita e bem recebida; tratamento igualitário da liderança a todos os funcionários, para que isso gere uma sensação de justiça e a perpetuação de uma cultura organizacional em que o assédio moral e as agressões não sejam toleradas.

\section{Metodologia}

Neste capítulo é apresentada a maneira pela qual a pesquisa foi realizada, bem como sua natureza, tipo e abordagem. Ademais, são explicitados os tipos dos dados utilizados, a forma como se deu a coleta dos dados e como os dados foram analisados. Ainda neste capítulo, é apresentado o estudo de caso para a pesquisa de campo e organização da análise.

\subsection{Natureza, Tipo e Abordagem Da Pesquisa}

Para a realização do presente trabalho fez-se necessárias diretrizes metodológicas a fim de se atingir os objetivos que a pesquisa se propôs inicialmente. A presente investigação possui natureza qualitativa, cujo objetivo foi traduzir e expressar os fenômenos que ocorrem no mundo social (MAANEN, 1979). Ademais, a pesquisa é do tipo descritiva e sua abordagem teórico-empírica, a qual descreve a situação encontrada a partir da aplicação de conceitos encontrados na teoria a situações de uma realidade empírica.

Na presente investigação foi realizado um estudo de caso, em que se procurou responder o porquê o assédio moral se manifesta com maior incidência em situações que envolvam mulheres em um ambiente de trabalho masculinizado. Sabe-se que sobre esse fenômeno há pouca possibilidade de controle e deverá ser analisado dentro do contexto da realidade dos trabalhadores. De acordo com Godoy (1995), o estudo de caso pode ser entendido como um tipo de pesquisa cujo objeto se constitui uma unidade que se analisa profundamente. Para a autora, o objetivo principal do estudo de caso é o exame detalhado de um determinado ambiente ou situação, proporcionando a vivência da realidade por meio da discussão.

Sendo assim, a presente investigação valeu-se de uma amostra de 5 postos de combustíveis da bandeira Shell em uma mesma rede na cidade de Maringá. A rede de postos de gasolina está presente no mercado maringaense há 15 anos, todos os postos estão localizados na região central da cidade, são geridos pela mesma administração e contam com lojas de conveniência. Dentre os 5 postos, 2 deles funcionam 24 horas.

\subsection{Tipos de Dados, Metódo de Coleta e Análise dos Dados}

Os tipos de dados que foram utilizados são dados primários, derivados de questionários semiestruturados que foram usados para a coleta de dados. Para Mattar (2005), dados primários são aqueles que ainda não foram 
coletados, ou seja, são pesquisados com o intuito de subsidiar necessidades particulares da pesquisa que está sendo desenvolvida. Nesse sentido, foram realizadas entrevistas com 9 funcionárias mulheres em 5 postos de combustíveis diferentes e pertencentes a mesma rede. As entrevistadas exercem cargos diversos, como o de frentista, caixa e zeladora e possuem a idade entre 27 e 44 anos, a maioria delas não possui ensino superior completo.

Ademais, foram também aplicadas as 9 funcionárias questionários semiestruturados, os quais questionavam acerca das situações mais frequentes de assédio moral. Esse questionário teve uma como base o instrumento Negative acts Questonnaire Revised (NAQ-R) e se propôs a avaliar o assédio moral, indicando 25 alternativas que sugerem episódios ofensivos sem utilizar o termo "assédio" em seu conteúdo.

No que diz respeito ao primeiro objetivo específico, compreender como a imagem da mulher é construída em ambientes de predominância masculina, na visão das mulheres entrevistadas, foi perguntado se elas se sentiam ou se enxergavam diferentes de alguma forma, por serem mulheres e trabalharem cercada por tantos homens. Ainda nesse sentido, as mulheres foram questionadas se acreditavam receber algum tipo de tratamento diferente de seus colegas de trabalho ou superiores pelo simples fato de serem mulheres.

Em seguida, a fim de contemplar o segundo objetivo específico da pesquisa, que consiste em identificar as situações que indicam a ocorrência do assédio moral contra as mulheres investigadas, foram questionadas possíveis situações cotidianas que ocorriam e rebaixavam, ofendiam ou agrediam as entrevistas e como esse tipo de situação afetava a vida pessoal e profissional dessas mulheres. Na última parte da entrevista, foi questionado que tipos de ações que a organização poderia empreitar no sentido de evitar a ocorrência do assédio moral, na percepção das mulheres investigadas.

A análise dos dados que foi empregada é a interpretativa, a qual busca o significado do texto no que tange a área de conhecimento pesquisada, identificando assim, os pressupostos explícitos, como os implícitos para construir uma argumentação e realizar uma análise crítica e reflexiva acerca da literatura pesquisada (SEVERINO, 2002). Por fim, o recorte da pesquisa é transversal uma vez que se foca em um único espaço de tempo, qual seja o ano de 2016.

\section{Apresentação, Análise e Discussão Dos Dados}

Nesta seção, serão apresentados os dados, bem como o resultados e análises obtidos na pesquisa de campo (entrevistas), confrontando-os com aquilo que a literatura existente disponibilizou sobre a temática.

\subsection{A Imagem da Mulher}

Em relação a construção da imagem da mulher em ambientes masculinizados, observou-se divergência de percepções de acordo com os cargos exercidos pelas mulheres. As frentistas entrevistadas afirmaram sofrer um certo grau de discriminação por serem mulheres e exercerem um cargo que majoritariamente é preenchido por homens. Dessa maneira, essas mulheres disseram que se sentem, por vezes, oprimidas por seus colegas homens por serem minorias nesse ambiente. No entanto, disseram não acreditarem ser incapazes de realizar qualquer tarefa que lhe sejam atribuídas, e, portanto, enxergam que possuem as mesmas habilidades e empenho que os homens quando exercem esse cargo. Com exceção de apenas uma entrevistada que exerce o cargo de frentista, a qual confessou sentir dificuldade algumas vezes de realizar as mesmas tarefas que os homens realizam no mesmo cargo, em virtude da força física que as tarefas inerentes desse cargo exigem da mulher. Entretanto, fora a limitação física, ela acredita que a força intelectual do homem e da mulher em nada diferem na execução do trabalho. A Frentista 2 revelou:

No meu ponto de vista, eu me vejo diferente sim. Quando você vai trabalhar de frentista, você tem que arcar com as consequências de pegar galão de 20, 30 litros. Minha força não é igual a dos meninos, mas eles não querem nem saber, você que se vire. Eu acho uma falta de consideração. Acontece assim, se você quer trabalhar em um lugar assim, você precisa correr atrás, ninguém te ajuda não. E se eu não consigo pegar peso, eles dizem que estou fazendo corpo mole.

Por outro lado, mulheres que exercem outros cargos, quando indagadas se enxergavam de uma maneira diferente naquele ambiente de trabalho, afirmaram se enxergar com as mesmas capacidades dos homens.

A Operadora de Caixa 2 respondeu: "Não me sinto diferente por ser mulher. E já foi o tempo que os homens enxergavam diferente, porque a gente trabalha mais que eles hoje em dia. Trabalhamos em casa, depois trabalhamos aqui e assim vai." Nesse mesmo sentido, concordou a Balconista 1: "Eu não sinto diferença nenhuma. Nunca percebi que os homens sintam essa diferença também, todos nós conseguimos fazer as memas coisas".

Percebe-se com isso, no caso pesquisado nesta rede de postos, um caminho de superação da discriminação da 
mulher em razão de gênero no ambiente de trabalho de predominância masculina, uma vez que a discrimanção está pautada na visão deturpada que as mulheres sejam inferiores por serem mulher.

As entrevistadas afirmaram que se veem capazes de trabalhar nas mesmas funções e realizando as mesmas tarefas que os homens e afirmaram ainda, que os homens também as enxergam da mesma maneira. Com isso, afasta-se aquilo que foi dito por Barreto (2002), que as pessoas mais propensas a se tornarem vítima do assédio moral são aquelas que apresentam diferenças com os padrões estabelecidos naquele ambiente, sendo a discriminação forte condição para perpetuação do assédio moral.

Refuta-se também, a ideia que tudo aquilo que é diferente e destoa em um cenário homogêneo se torna vulnerável a discriminação e, portanto, passível de se tornar situações de assédio moral. A diversidade tem trazido benefícios para o ambiente de trabalho e as mulheres que ali trabalham se veem, no geral, valorizadas e reconhecidas por seus colegas homens. Muitas relataram ganharem elogios pelo empenho e dedicação ao trabalho e disseram que alguns colegas afirmam que as mulheres são mais enérgicas e proativas na hora de assumir tarefas. "Eles dizem às vezes que uma de nós faz o trabalho que dois deles não conseguiriam fazer", brincou uma das entrevistadas que exerce a função de operadora de caixa.

Diante dos dados coletados, observou-se a imagem da mulher ainda é distorcida em razão de gênero em alguns cargos, como o de frentista, nos postos de gasolina, embora em menor quantidade. Atrela-se a maior incidência de episódios que discriminam as mulheres ao cargo que ela exerce. Dessa forma, entende-se que o cargo possa ser um fator que influencie a prática do assédio moral. Trabalhos considerados mais pesados e que recrutem maior esforço físico, como o de frentista, ainda são lacunas para que mulheres e homens se enxerguem em uma hierarquia.

Quadro 1: Imagem da mulher.

\begin{tabular}{|l|l|l|}
\hline Cargo & Como a mulher se enxerga & $\begin{array}{l}\text { Como a mulher acredita que os } \\
\text { homens a enxergam }\end{array}$ \\
\hline Frentista 1 & $\begin{array}{l}\text { Acredita ser capaz de realizar toda } \\
\text { atividade que o homem também é } \\
\text { capaz. }\end{array}$ & $\begin{array}{l}\text { Acredita ser discriminada pelos } \\
\text { colegas homens em razão do } \\
\text { gênero. }\end{array}$ \\
\hline Operadora de caixa 1 & $\begin{array}{l}\text { Acredita ser capaz de realizar toda } \\
\text { atividade que o homem também é } \\
\text { capaz. }\end{array}$ & $\begin{array}{l}\text { Acredita ser valorizada e tem seu } \\
\text { trabalho reconhecido pelos colegas } \\
\text { homens. }\end{array}$ \\
\hline Balconista 1 & $\begin{array}{l}\text { Acredita ser capaz de realizar toda } \\
\text { atividade que o homem também é } \\
\text { capaz. }\end{array}$ & $\begin{array}{l}\text { Acredita ser valorizada e tem seu } \\
\text { trabalho reconhecido pelos colegas } \\
\text { homens. }\end{array}$ \\
\hline Operadora de caixa 2 & $\begin{array}{l}\text { Acredita ser capaz de realizar toda } \\
\text { atividade que o homem também é } \\
\text { capaz. }\end{array}$ & $\begin{array}{l}\text { Acredita ser valorizada e tem seu } \\
\text { trabalho reconhecido pelos colegas } \\
\text { homens. }\end{array}$ \\
\hline Frentista 2 & $\begin{array}{l}\text { Acredita ser capaz de realizar toda } \\
\text { atividade que o homem também é } \\
\text { capaz. }\end{array}$ & $\begin{array}{l}\text { Acredita ser discriminada pelos } \\
\text { colegas homens em razão do } \\
\text { gênero. }\end{array}$ \\
\hline Operadora de caixa 3 & $\begin{array}{l}\text { Acredita ser capaz de realizar toda } \\
\text { atividade que o homem também é } \\
\text { capaz. }\end{array}$ & $\begin{array}{l}\text { Acredita ser valorizada e tem seu } \\
\text { trabalho reconhecido pelos colegas } \\
\text { homens. }\end{array}$ \\
\hline Frentista 3 & $\begin{array}{l}\text { Não acredita ser capaz de realizar } \\
\text { toda atividade que o homem } \\
\text { também é capaz. }\end{array}$ & $\begin{array}{l}\text { Acredita ser discriminada pelos } \\
\text { colegas homens em razão do } \\
\text { gênero. }\end{array}$ \\
\hline Zeladora 1 & $\begin{array}{l}\text { Acredita ser capaz de realizar toda } \\
\text { atividade que o homem também é } \\
\text { capaz. }\end{array}$ & $\begin{array}{l}\text { Acredita ser discriminada pelos } \\
\text { colegas homens em razão do } \\
\text { gênero. }\end{array}$ \\
\hline Operadora de caixa 4 & $\begin{array}{l}\text { Acredita ser capaz de realizar toda } \\
\text { atividade que o homem também é } \\
\text { capaz. }\end{array}$ & $\begin{array}{l}\text { Acredita ser valorizada e tem seu } \\
\text { trabalho reconhecido pelos colegas } \\
\text { homens. }\end{array}$ \\
\hline
\end{tabular}

Fonte: Elaborado pelo autor

Contudo, de modo geral, dentre as 9 entrevistadas, a maioria das mulheres declararam desfrutar de um ambiente de trabalho saudável, se veem reconhecidas por seu trabalho e respeitadas pelos seus colegas. Um resumo da opinião das entrevistadas é disposto no Quadro 1. As entrevistatadas acreditam que estão aptas para desenvolver as mesmas tarefas que são atribuídas aos homens e que o olhar dos homens para elas enquanto profissionais tem amadurecido, no sentido de afastar a discriminação e reconhecer a capacidade da mulher no ambiente de trabalho, 
ainda que ela seja minoria naquele meio. Essa constatação contraria a literatura sobre assunto até então produzida, Saffioti (1992) afirmou que as mulheres são também portadoras do machismo e minam sua imagem por acreditarem serem desqualificadas se comparadas com atribuições masculinas. Além disso, afirmou que a mulher por não se enquadrar no padrão pré-estabelecido para aquele lugar, poderia ter sobre si uma imagem fragilizada pelo machismo, entretanto, essas afirmações não representam a realidade dos achados.

\subsection{Situações Em Que Ocorrem o Assédio Moral}

No que diz respeito aos episódios que indicam a ocorrência do assédio moral, apenas as frentistas e uma zeladora foram capazes de relatar situações reiteradas de discriminação ou desqualificação do trabalho. Elas alegaram sofrer com os comentários dos seus colegas de trabalho, clientes e superiores, e em especial, aquelas que realizam trabalho noturno são desrespeitadas durante o seu trabalho e recebem diversos convites inoportunos. Os comentários são eivados de conotações machistas e sexistas, sendo as mulheres vítimas também do assédio sexual nesse contexto, tal constatação vai ao encontro do que Hirigoyen (2005) afirmava em suas pesquisas, a mulher sofre assédio de uma maneira diferente daquela que os homens são assediados.

Constatou-se que o período em que trabalham as mulheres é mais um fator relevante na determinação da ocorrência do assédio moral, uma vez que se observa que as 4 mulheres que trabalham no período noturno admitiram passar por situação constrangedoras pelo fato de serem mulheres (Quadro 2).

Quadro 2: Ocorrência do assédio moral.

\begin{tabular}{|l|l|l|}
\hline Cargo & Período em que trabalha & $\begin{array}{l}\text { Admite passar por situações } \\
\text { ofensivas }\end{array}$ \\
\hline Frentista 1 & Noturno & Sim \\
\hline Operadora de Caixa 1 & Diurno & Não \\
\hline Balconista 1 & Diurno & Não \\
\hline Operadora de Caixa 2 & Diurno & Não \\
\hline Frentista 2 & Noturno & Sim \\
\hline Operadora de Caixa 3 & Diurno & Não \\
\hline Frentista 3 & Noturno & Sim \\
\hline Zeladora 1 & Noturno & Sim \\
\hline Operadora de Caixa 4 & Diurno & Não \\
\hline Fon : Ela
\end{tabular}

Fonte: Elaborado pelo autor

A Frentista 1 relatou que "muitos homens acham que por estarmos aqui de madrugada somos mulheres fáceis, que não temos família ou que estamos aqui por diversão. Na realidade, trabalhar a noite não é fácil, faço porque preciso, justamente porque tenho família e devo ajudar a sustentar".

Em entrevista, a Frentista 2 admitiu se sentir constrangida perante seus colegas, já que toda vez que comete algum erro na execução das suas tarefas, comentários como "isso não é trabalho para mulher" são feitos por seus colegas de trabalho, mas quando algum homem comente o mesmo erro que ela, nada é dito a respeito.

Ademais, em função da jornada de trabalho noturna de algumas frentistas, elas alegam serem discriminadas e sofrerem preconceito no seu meio social por não estarem em casa com suas famílias aos finais de semana, por exemplo, e são jugadas como mães e esposas ausentes por passarem a noite trabalhando nos postos de combustíveis. Essa situação pode ser identificada na fala da Frentista 1: "já ouvi muito assim, devido a eu trabalhar direto, sábado, domingo e feriado, as pessoas dizem, você tinha que arrumar outro emprego e pensar mais na sua família". Também nessa esteira, a Frentista 3 afirmou: " na minha própria casa eu sinto um pouco de preconceito, meus filhos não gostam que eu trabalhe aqui no posto".

Por outro lado, as mulheres que exercem cargos como o de caixa e zeladora disseram não sofrer nenhum tipo de discriminação em razão de gênero. A Operadora de Caixa 3 afirmou trabalhar em postos de combustíveis há mais de 11 anos e relatou a transformação do ambiente de trabalho ao longo desses anos. Em entrevista disse que: "antigamente existia o preconceito com as mulheres que trabalhavam em posto, no sentido de ser mulher vulgar, agora não, eu vejo que está mais tranquilo, o pessoal tá respeitando bastante". 
Quadro 3: Situações que indicam assédio moral.

\begin{tabular}{|l|l|}
\hline Número de mulheres que se queixaram & Situação de assédio moral \\
\hline 4 mulheres & Suas opiniões e pontos de vista foram ignorados. \\
\hline 4 mulheres & Recebeu críticas constantes ao seu trabalho ou esforço. \\
\hline 3 mulheres & Foi constantemente lembrado dos erros e omissões. \\
\hline 3 mulheres & $\begin{array}{l}\text { Foram feitos comentários ofensivos e insultos sobre } \\
\text { suas atitudes e comportamentos }\end{array}$ \\
\hline 2 mulheres & $\begin{array}{l}\text { Foram interrompidas constantemente em reuniões ou } \\
\text { em diálogos }\end{array}$ \\
\hline 1 mulher & Foi alvo de agressividade ou raiva gratuita. \\
\hline
\end{tabular}

Fonte: Elaborado pelo autor

A Balconista 1 também declarou: "no passado as meninas sofriam, porque os homens chegavam e achavam que podiam fazer qualquer tipo de comentário, daí os maridos não deixavam as mulheres trabalharem em postos". Em relação as situações que caracterizam o assédio moral, foram disponibilizadas em questionários para as entrevistadas, 32 situações que indicavam a ocorrência de assédio moral sem que o termo "assédio" fosse utilizado. Os episódios mais assinalados e as circunstâncias que mais apresentaram queixas são disponibilizadas no Quadro 3.

Os dados coletados confirmam aquilo que Guedes (2004) classifica como algumas atitudes que o assédio moral está presente, como se recusar a comunicar-se, desqualificar e constranger alguém a fim de destruir sua auto estima e cortar as relações sociais. Pineul e Zabala (2003) indicam também como assédio moral comportamentos de omissão de informações, recusa de comunicação, isolamento e discriminação, desqualificação dos serviços e indução ao erro. $\mathrm{O}$ que a literatura aponta como as situações mais comum de assédio moral também são as situações mais comuns vivenciadas na realidade do ambiente de trabalho dessas mulheres, casando a teoria com a prática no que tange esse ponto de discussão.

Percebeu-se com isso que as situações em que ocorrem o assédio moral estão concentradas majoritariamente no período noturno em que o ambiente se torna mais hostil para as mulheres. Em virtude de o trabalho ser realizado a noite, os homens tendem a assediá-las moralmente e sexualmente, por meio de comentários ofensivos e convites inoportunos feitos pelos colegas e clientes.

O período em que trabalha a mulher pode ser considerada outra lacuna em que o assédio moral se perpetua, demonstrando ainda a necessidade de evolução no pensamento da sociedade, tanto do homem, como o da mulher, uma vez que as mulheres disseram se sentirem discriminadas também por outras mulheres, que as condenam pelo fato de simplesmente exercerem trabalho noturno em um ambiente predominantemente masculinizado.

\subsection{Medidas Para Evitar o Assédio Moral}

Após a coleta de dados, percebeu-se que existe treinamento e desenvolvimento nas empresas investigadas e que os funcionários são instruídos na maneira em que devem se relacionar uns com os outros. As funcionárias afirmaram participarem de reuniões em conjunto com os homens que ali trabalham, em que valores como igualdade e respeito são disseminados. Todavia, é perceptível ainda os vestígios de uma sociedade machistas impregnando o ambiente de trabalho e evidenciando que tais medidas que a empresa adota para criar um clima social respeitoso não tem sido suficientes. A Frentista 1 relatou:

\footnotetext{
Mesmo que haja treinamento, haja conversa, haja diálogo, vai muito do caráter da pessoa, é uma educação que vem de casa. Por mais que o gerente cobre isso, na frente dele sempre vai ser uma coisa, mas por trás você sabe como é. Tinha que existir alguma fiscalização".
}

Em entrevista, as 9 mulheres investigadas afirmaram não comunicar a organização em relação as ofensas sofridas no período laboral. Quando questionadas sobre o motivo de tal omissão, a maioria delas a apresentou a falta de costume, o medo de criar um embate ou ainda o medo de retaliação em caso de reclamação aos gerentes. Essa situação foi sugerida na fala da Frentista 2: "não acho que reclamar dos comentários faça com que algo mude no comportamento dos meninos, é possível ainda que eles se revoltem contra mim, não quero causar mais problemas".

As entrevistadas, em sua maioria, admitiram sentirem falta de alguma punição, como por exemplo, uma advertência, para os atos discriminatórios. Sugeriram uma fiscalização maior por parte de gerência para se coibir o assédio moral horizontal, aquele que ocorre entre colegas de trabalho de uma mesma função. Acreditam que a penalização por esses atos de desvalorização do trabalho poderia ser capaz de eliminar ou diminuir os comentários ofensivos que a elas são dirigidos. 
Entretanto é impossível que sejam adotadas medidas efetivas contra o assédio moral antes que ele seja formalizado e encarado como um problema concreto. Desse modo, entende-se primordial em um primeiro momento a criação de um canal de comunicação sólido entre a organização e as mulheres vítimas de assédio que as leve ao encorajamento da formalização do problema. Apenas quando sentirem segurança na organização e na maneira com o qual o problema do assédio vai ser encarado pelos gestores que se acredita que as funcionárias dos postos se sentirão à vontade para denunciar as ofensas e situações hostis que venham a ser submetidas durante o seu trabalho.

Em um segundo plano, há que se falar em quais atitudes a organização deverá tomar quando o assédio moral for objeto de denúncia ou reclamação dentro da empresa. Quando o problema for alvo de atenção e for lidado de maneira categórica, numa lógica de ação e reação, restando sempre consequências sérias para aqueles que forem disseminadores de atitudes que configuram o assédio moral, as mulheres se sentirão mais seguras para formalizar os episódios que as incomodam e os homens mais cuidadosos em seus comentários e brincadeiras.

Sugere-se ainda por parte da organização a fiscalização do ambiente de trabalho, inibindo condutas agressivas e desrespeitosas, a fim de proporcionar a todos os envolvidos um local saudável e respeitoso para se trabalhar.

O resultado encontrado harmoniza com a literatura pesquisada, já que autores como Freitas, Holoani e Barreto (2008) concordam que a erradicação da cultura da impunidade é primordial para se dar um passo em direção a criação de um ambiente de trabalho mais igualitário e salutar e que essa empreitada é uma tarefa coletiva, exigindo de esforços e cooperação dos ocupantes de cargos mais elevados para fiscalizar e punir tais agressões. Assim, quando todos os membros da organização estiverem cientes dos prejuízos do assédio moral e que ele será lidado de forma efetiva, o empregador terá condições de promover uma gestão voltada para a proteção da segurança e saúde de seus empregados, trazendo assim, um senso de justiça.

Por fim, assim como Einarsen e Hoel (2008) afirmaram a prevenção do assédio moral abarca elementos como a criação de um clima social respeitoso, em que a diversidade seja aceita e bem recebida; tratamento igualitário da liderança a todos os funcionários, para que isso gere uma sensação de justiça; olhar atento dos gestores para necessidades pessoais e vulnerabilidade dos membros da organização, bem como estabelecimento e perpetuação de uma cultura organizacional em que o assédio moral e as agressões não sejam toleradas.

\section{Conclusão}

O presente estudo trouxe à tona a influência gênero sobre a ocorrência do assédio moral, possibilitando assim, entender a vulnerabilidade feminina no ambiente de trabalho. A violência psicológica tem tomado proporções significativas, situações essas que ferem os direitos da personalidade dos trabalhadores, violando o Princípio da Dignidade Humana previsto na Carta Magna.

Resultou-se escassa a legislação brasileira que abarque a temática, uma vez que não existe uma legislação federal expressa que vise coibir a prática das agressões, restando assim imatura a legislação no que diz respeito a penalização do assédio moral, dificultando, portanto, o combate a esse tipo de violência.

O ensaio teórico levantado a fim de esclarecer a relação entre o gênero e o assédio moral evidenciou que as mulheres são as vítimas mais frequentes do assédio moral, como também são assediadas de maneira diferente dos homens, uma vez que as agressões possuem conotações machistas ou sexistas. Muito embora, entende-se que a legislação atual assegure que homens e mulheres são iguais em direitos e obrigações, buscando afastar a discriminação em razão de sexo, é possível notar que o ambiente de trabalho ainda remonta traços de uma sociedade marcada pelo machismo e que ampara argumentos de comportamentos hostis no determinismo biológico.

Em relação ao objetivo específico relacionado a compreensão de como a imagem da mulher é construída em ambientes de predominância masculina, os achados apontam que as mulheres se veem capazes de realizar qualquer atividade que os homens possam desenvolver no ambiente de trabalho. Com exceção apenas de algumas atividades exigidas em cargos como o de frentista, as quais demantam força física e limitam o trabalho das mulheres. $\mathrm{Na}$ visão das entrevistas, elas se reconhecem como peças fundamentais na organização e se sentem reconhecidas, na maioria das vezes, pelos homens que com elas trabalham.

No que tange ao objetivo específico relacionado a identificar as situações que indicam a ocorrência do assédio moral, as situações mais recorrentes de assédio são quando as mulheres percebem que suas opiniões e pontos de vistas estão sendo ignorados e ainda quando recebem críticas constantes ao seu trabalho e esforço. Por meio das entrevistas, observou-se que as mulheres se queixaram sobre o assédio sexual, uma vez que sofrem com convites inoportunos e comentários sexistas e machistas quando estão trabalhando no cargo de Frentista.

A pesquisa de campo parcialmente comprovou o que a literatura aponta sobre a temática. É bem verdade que as 
mulheres ainda são assediadas de maneira diferente dos homens, contudo, foi possível constatar uma transformação no ambiente de trabalho dos postos de combustíveis da rede investigada no decorrer dos anos. $\mathrm{O}$ cenário atual registrou uma evolução na mentalidade dos homens e mulheres, trazendo um senso maior de igualdade e respeito. Constatou-se também, que em razão do cargo exercido e do horário em que se trabalha, o meio de torna mais propenso para a ocorrência do assédio. Frentistas são mais assediadas que mulheres que trabalham como Operadoras de Caixa, Balconistas nas lojas de conveniência ou como Zeladoras. Resultou ainda que mulheres que trabalham no período da noite e madrugada são mais assediadas que aquelas que trabalham apenas no período do dia.

Por fim, acerca do objetivo específico relacionado a descrever medidas que podem ser tomadas para evitar o assédio moral, no caso investigado, sugere-se a necessidade da criação de canal de comunicação eficaz, em que as mulheres se sintam encorajadas a formalizar as ofensas que a elas são dirigidas, uma vez que todas confessaram nunca terem se queixados das situações de assédio moral. E quando formalizado, é necessário que o assédio moral seja encarado de maneira séria, trazendo consequências reais para aqueles que contribuírem para a propagação de tais situações, como advertências.

\section{Referências}

BARRETO, M. S. Violência, saúde e trabalho: uma jornada de humilhações. São Paulo: EDUC, 2006.

BARRETO, M. S. Assédio moral: risco não visível no ambiente de trabalho. 2008. Disponível em: $<$ http://www.fiocruz.br/ccs/cgi/cgilua.exe/sys/start.htm?infoid=1935\&si d=3>. Acesso em: 10 de julho de 2016.

CIAMPA, A. C. A Estoria do Severino e a história da Severina. São Paulo: Brasiliense, 1990.

CHRIST, H. D. Estudo de adaptação e fidedignidade do Questionário de Atos Negativos Revisado (QAN-R) para o português do Brasil. Porto Alegre, 2012. Dissertação (Mestrado em Psicologia Clínica) - Faculdade de Psicologia, PUCRS.

DINIZ, M. H. Curso de direito civil brasileiro. v. 1: teoria geral do direito civil. 18 ed. atualizada de acordo com o novo código civil (Lei nº. 10.406, de 10-1-2002). São Paulo: Saraiva, 2002.

DINIZ, M. H. Curso de direito civil brasileiro, vol. 1: teoria geral do direito civil - 26 ed. reformulada - São Paulo: Saraiva, 2009.

DOMINGUES, M.; HEUBEL, M. T. C. D.; ABEL, I. J. Bases metodológicas para o trabalho científico: para alunos iniciantes. Bauru: EDUSC, 2003.

DOMINGUES, M.; HEUBEL, M. T. C. D.; ABEL, I. J. Bases metodológicas para o trabalho científico: para alunos iniciantes. Bauru: EDUSC, 2003.

EINARSEN, S., HOEL, H., ZAPF, D. and COOPER, C. The concept of bullying at work, 2003.

GOLDANI, A.; Família e Gêneros: uma proposta para avaliar (des)igualdades. Campinas, 2000.

GODOY, A. S., Introdução à pesquisa qualitativa e suas possibilidades, In Revista de Administração de Empresas, v. 35, n/2, Mar./Abr. 1995.

GUEDES, M. N. (2004) Terror psicológico no trabalho. Editora LTr.

HALL, S. A identidade cultural na pós-modernidade. Rio de Janeiro: DP\&A, 2002.

HELOANI, R.; BARRETO, M. Assédio moral no trabalho. São Paulo: Cengage Learning, 2008

HIRIGOYEN, M.-F. Assédio moral: a violência perversa no cotidiano. 10a ed. Rio de Janeiro: Bertrand Brasil, 2008.

HIRIGOYEN, M.-F. Mal-estar no trabalho: redefinindo o assédio moral. 3a ed. Rio de Janeiro: Bertrand Brasil, 2006.

LAURETIS, T. A tecnologia do gênero. In: HOLLANDA, B.H. Tendências e impasses: o feminismo como crítica da cultura. Rio de Janeiro: Rocco, 1994.

LEYMANN, H. Mobbing and Psychological Terror at Workplaces. Violence and Victims, 1990. Vol. 5, no 2, p. 119-126.

LEYMANN, H. 1996. "The Content and Development of Mobbing at Work." European Journal of Work and Organizational Psychology. 5:2, pp.165-184. 
MAANEN, J. V. Reclaiming qualitative methods for orgazational research: a preface, In Administrative Science Quarterly, vol. 24, n4, December, 1979.

MACHADO, L. Z. Perspectivas em confronto: relações de gênero ou patriarcado contemporâneo? Simpósio Relações de Gênero ou Patriarcado Contemporâneo. 52 $2^{\mathrm{a}}$ Reunião Brasileira para o Progresso da Ciência: Sociedade Brasileira de Sociologia, Brasília, 2002.

NASCIMENTO, A. M. Iniciação ao Direito do Trabalho. 37 ed. São Paulo: LTr, 2012.

PINUEL, I.; ZABALA, A. (2003). Mobbing: como sobreviver ao assédio psicológico no trabalho. Loyola.

SAFFIOTI, H. I. B. Rearticulando gênero e classe social. In: COSTA, A.O. ; BRUSCHINI, C. (Orgs.) Uma Questão de gênero. São Paulo ; Rio de Janeiro: Rosa dos Tempos, 1992.

SALES, A.; FREITAS, R.; MACEDO, S.; NEDER, M.; Tudo muda, mas nada muda? O discurso sobre a imagem da mulher nas organizações. Rio de Janeiro, 2013

UFSC. Universidade Federal de Santa Catarina. Assédio Moral no Trabalho. Florianópolis, 2009. Disponível em: $<$ http://www.assediomoral.ufsc.br $>$. Acesso em: 20 de junho 2016. 